\title{
The Role of Periodontal Disease in Preterm Labour - A Prospective Cohort Study (A Path Analysis) from Iran
}

\author{
Mohammad Mahdi Farshad ${ }^{1}$, Afshin Khorsand ${ }^{2}$, Masoomeh Kheirkhah ${ }^{3}$, Ahmad Reza Shamshiri ${ }^{4}$, Fatemeh Farshad ${ }^{5}$ \\ ${ }^{1}$ Department of Oral and Maxillofacial Surgery, School of Dentistry, Shiraz University of Medical Sciences, Shiraz, Iran. \\ ${ }^{2}$ Department of Periodontics, Tehran University of Medical Sciences, Tehran, Iran. ${ }^{3}$ Department of Midwifery and \\ Reproductive Health and Pregnancy, Nursing Care Research Center, School of Nursing and Midwifery, Iran University \\ of Medical Sciences, Tehran, Iran. ${ }^{4}$ Department of Community Oral Health, School of Dentistry, Tehran University of \\ Medical Sciences, Tehran, Iran. ${ }^{5}$ Department of Dental Surgery, School of Dentistry, Tehran University of Medical \\ Sciences, Tehran, Iran.
}

\section{ABSTRACT}

\section{BACKGROUND}

Periodontal infections are the most common oral diseases in pregnancy. This condition can cause complications during pregnancy. Therefore, this study was designed to determine the factors affecting preterm birth and their relationship with periodontal diseases.

\section{METHODS}

This was a prospective cohort study and the population, consisted of old women in the age group of 18 - 45 years attending prenatal care centers in their second trimester of pregnancy. After obtaining informed and free consent from the female parent, a periodontal examination was performed and her medical information was recorded. Examination of Rumford's teeth was performed to assess the severity of gingivitis, plaque, calculus, and attachment loss. AMOS software was used to investigate the association between preterm labor and delivery and to provide a conceptual model.

\section{RESULTS}

The consequences showed a direct association between preterm labour and factors, such as attachment loss, calculus, bleeding on probing (BOP), age, current diabetes, gestational diabetes, gestational hypertension, lack of calcium, folic acid, and iron supplementation, mothers' depression, polyhydramnios, smoking severity, and history of premature rupture of the membrane. The results also indicated an indirect relationship between irregular tooth brushing and preterm birth.

\section{CONCLUSIONS}

Attachment loss, calculus, bleeding on probing, are directly related to premature labour and irregular tooth brushing is indirectly associated with early birth. Due to the direct relationship between periodontal diseases and preterm delivery, regular brushing, oral hygiene, oral examinations during pregnancy and follow-up treatment of periodontal disease during pregnancy are recommended.

\section{KEY WORDS}

Periodontal Disease, Preterm Labour, Cohort Study, Path Analysis, Pregnancy
Corresponding Author:

Dr. Masoomeh Kheirkhah, Department of Midwifery and Reproductive Health and Pregnancy, School of Nursing and Midwifery, Iran University of Medical Sciences, Tehran, Iran.

E-mail: Kheirkhah.m@iums.ac.ir

DOI: $10.14260 / j e m d s / 2021 / 262$

How to Cite This Article:

Farshad MM, Khorsand A, Kheirkhah M, et al. The role of periodontal disease in preterm labor - a prospective cohort study (a path analysis) from iran.J Evolution Med Dent Sci 2021;10(17):1228-1234, DOI: 10.14260/jemds/2021/262

Submission 15-12-2020,

Peer Review 19-02-2021,

Acceptance 25-02-2021,

Published 26-04-2021.

Copyright (C) 2021 Mohammad Mahdi Farshad et al. This is an open access article distributed under Creative Commons Attribution License [Attribution 4.0 International (CC BY 4.0)] 


\section{BACKGROUND}

Periodontal disease is a heterogeneous group of infections that can lead to tooth loss. Localization of inflammatory mediators in periodontal tissues may lead to reversible inflammation (gingivitis) or irreversible local tissue destruction (periodontitis). ${ }^{1}$ The prevalence of mild periodontitis is reported to be $35 \%$ and moderate to severe periodontal disease represents $11 \%$. It is a global epidemic which causes disability, speech impairment, negative self-esteem, and reduced quality of life. ${ }^{2}$ Oral health and its relationship to the health of the body system are one of the health concerns. $90 \%$ of the population are affected by gingivitis or periodontal disease. There is evidence that periodontal condition is associated with heart disease, diabetes, respiratory infection and adverse outcomes. The prevalence of periodontitis in pregnant women is $(40 \%)^{3}$ and hormonal changes through gestation promote the inflammatory response and facilitate the occurrence of periodontal disease. Due to hormonal changes, $50-70 \%$ of women develop gingivitis during pregnancy. Elevated levels of progesterone and oestrogen in plasma during pregnancy can affect the periodontal structure by interfering with the micro flora of the gums and the mother's immune system, facilitating the production of inflammatory mediators. ${ }^{4}$ Gill et al. (2019) evaluated the diagnostic indicators of periodontal disease in the third trimester of pregnancy, and the results showed that the severity of periodontitis in pregnant women is related to the frequency of brushing and PI (Plaque Index). A positive association between increased C-reactive protein (CRP) in pregnancy and bleeding on probing (BOP) and Probing pocket depth (PPD) has been reported. ${ }^{5}$ Maternal periodontal disease, may change the cytokines and hormonal status of the mother during pregnancy. It can cause preterm childbirth and lack of optimal infant development. ${ }^{6}$ Preterm delivery complications are responsible for one-third of newborn deaths worldwide and its combinations induce permanent disabilities, cerebral palsy, learning disabilities, and vision and hearing disorders, putting a heavy burden on the family and society. ${ }^{7}$ Some investigations of periodontal disease associated with negative outcomes include preterm delivery, low birth weight, intrauterine growth restriction, and preeclampsia. ${ }^{8}$ However, a study by Lohsoonthorn (2009) did not provide convincing evidence on the association between periodontal diseases and premature delivery. There are conflicting results about periodontal disease and preterm labor. Recognizing the direct and indirect risk factors for preterm birth is important, and the study was designed and implemented for this reason. The current study was conducted to determine the direct and indirect factors affecting preterm delivery with an emphasis on periodontal factors.

\section{METHODS}

This prospective cohort study was conducted from September 2016 to December 2017 at the prenatal care unit in Imam Khomeini (RA) hospital, affiliated with Tehran University of Medical Sciences.

\section{Inclusion and Exclusion Criteria}

The population of the study consisted of pregnant women in the second trimester of pregnancy; referred to prenatal clinic in Imam Khomeini hospital, women aged 18 to 45 years with gestational age of 14 - 28 weeks were included in the study, and those who failed to continue cooperation, or answer questions in the research process or had multiple pregnancies were excluded.

After getting permission from the university ethics committee and receiving the letter of introduction from the deputy of education and obtaining permission from the hospital officials, the researcher visited to the prenatal clinic. After introducing himself and explaining the goals of the study, he gave an informed consent from to eligible mothers to read and sign it. Demographic, medical, and reproductive information were recorded from the mother's file, and the periodontal examination was performed at the clinic, and the mothers' telephone numbers were recorded to track the outcome of the pregnancy on the research data collection form. In the periodontal examination, the researcher assessed six Rumford's teeth (maxillary first right molar, left maxillary central incisor, maxillary left first premolar, left mandibular first molars, mandibular right central incisor, and mandibular right first premolar). Then gingival inflammation around the teeth were assessed and the score allocated to each tooth ranged from G0 - G3, meaning that G0 indicated the absence of inflammation and G3 referred to a severe gingivitis. Moreover, mesial, facial, lingual, and distal surfaces of the teeth, the distance from the cementum enamel junction (CEJ), and the distance from the edge of the free gingival margin to the base of the free gingival were calculated.

If the free edge of the gums was on the cementum, its distance from the CEJ was recorded as a negative number. The distance from the CEJ to the base of the sulcus was calculated by subtracting the two numbers. Rumford's teeth method was used for calculating the distance, as the indirect method for calculating the amount of periodontal attachment loss. The assessment was based on the periodontal disease index (PDI) for each tooth and gingival inflammation and probing depth of CEJ. If there was no gingival extension of the apical to the CEJ, the PDI score was considered for dental and gingival scores. If gingiva below CEJ to be extended $3 \mathrm{~mm}$ or less, then PDI score 4 was assigned. PDI score 5 and 6 were assigned for the teeth with values of 3 to $6 \mathrm{~mm}$, and greater than $6 \mathrm{~mm}$, respectively. PDI was calculated by summing all numeric values divided by the number of the examined teeth. The missing teeth were not replaced by another tooth. To check the plaque, zero was assigned for the absence of plaque.

In case of plaque in the proximal region of the gingival margin or at least half of one-third of the facial or lingual gingival score 1 was given, if plaque concealed more than onethird and less than two-thirds of the facial or lingual surface score 2 was assigned, and if there were more than two-thirds of plaque covering a lingual surface of the tooth, score 3 was given. To investigate calculus, the absence of gingival calculus received zero score, the gingival calculus score of only slightly less than $1 \mathrm{~mm}$ under the gingival margin received grade 1 , the average value of above and below the gum calculus or calculus just below the gingiva received grade 2 and plenty of calculus above and below the gum has received a score of 3 . 
To prevent the loss of the samples after the oral examination, the contact number of the researcher was given to mothers in case they need to contact the researcher for further guidance. Moreover, mothers' addresses were recorded in the check lists. Then, they were asked to report their labour. If the mother did not call, the researcher contacted her a few days after the expected date of delivery. Maternal outcomes were assessed by telephone and follow up on the maternity consequences.

\section{Statistical Analysis}

Given the sample size to estimate the frequency of preterm birth in the Iranian population by $20 \%{ }^{9}$ and for a $15 \%$ difference test between mothers with periodontal disease and mothers without periodontal disease and the level of statistical confidence $95 \%$ and statistical power of $80 \%$, at least 112 samples per group were required. Mothers with periodontal disease compared to those without the disease in the study population was 1 to 3, 299 pregnant women, 224 pregnant women without periodontal disease and 75 pregnant women with periodontal disease participated in the study. According to the formula of unequal groups, with the same level of confidence and statistical ability, we were able to test the assumption of study.

$\frac{1}{\mathrm{n}_{2}}=\frac{2}{\mathrm{n}} ; \mathrm{n}_{1}=3 \mathrm{n}_{2} ; \mathrm{n}=112 \Rightarrow \mathrm{n}_{1} \approx 224, \mathrm{n}_{2} \approx 75$

The researcher followed up on the consequences of birth by phone. To prevent the loss of example size, sampling comprised $20 \%$ greater than the sample size. In order to prevent bias, all eligible people were included in the study. All participants were contacted for follow-up immediately after delivery and significant implications were assessed. Therefore, we did not have a selection bias, and a bias in information, and recall in this study. To analyse the data, variables were classified as relative frequency (\%), and quantitative variable were reported as Mean \pm SD. The analysis of "a path" used to investigate the association between risk factors on preterm birth. The variables studied, in addition to the direct effect on the measured outcome, also had a statistical and sometimes causal association with each other, which were ignored in regression analysis of these relationships. A path analysis was used to measure the direct and indirect effects of variables on preterm labour. In this study, the outcome variable quantified in the model and the generalized least square model were used to estimate the coefficients, and the Monte Carlo method was used to estimate the "90 \%" confidence limit of the estimates. Details of the analysis and model fit statistics are reported in the results section. The statistical significance was less than 0.05 .

\section{RESULTS}

Mothers with periodontal disease, $35.94 \%$ were under 24 years, $8.33 \%$ were poor and had financial problems, and 19.23 $\%$ had an average economic situation. $32.70 \%$ of mothers did not use calcium supplementation, $43.33 \%$ had mood disorders, $66.67 \%$, had hypertension in pregnancy, $54.55 \%$ had gestational diabetes mellitus (GDM), $81.82 \%$ had preeclampsia, $42.86 \%$ had periodontal attachment loss, 29.41 $\%$ of mothers with less than $1 \mathrm{~mm}$, and $23.58 \%$ with the average amount of calculus in sub gingival or supra and sub gingival calculus had preterm birth. It was found that the following factors increased the risk of premature birth: age less than 24 years, (4.49 times), lack of calcium supplement (0.49 times), history of mood disorders (2.34 times), and hypertension during pregnancy (6.53 times). Furthermore, gestational diabetes and preeclampsia, increased the risk of premature birth 3.52 and 13.96 times, respectively.

\begin{tabular}{|c|c|c|c|c|c|c|c|c|}
\hline \multirow{4}{*}{ Characteristics } & \multicolumn{8}{|c|}{ Total Effects } \\
\hline & \multirow{2}{*}{\multicolumn{4}{|c|}{$\begin{array}{c}\text { Unstandardized } \\
90 \% \mathrm{CI}\end{array}$}} & \multirow{2}{*}{\multicolumn{4}{|c|}{$\begin{array}{c}\text { Standardized } \\
90 \% \mathrm{CI}\end{array}$}} \\
\hline & & & & & & & & \\
\hline & Effect & Lower & Upper & $\mathbf{P}$ & Effect & Lower & Upper & $\mathbf{P}$ \\
\hline Age & 0.425 & 0.243 & 0.623 & 0.001 & 0.208 & 0.117 & 0.299 & 0.001 \\
\hline FE supplementation & -2.166 & -8.226 & 4.256 & 0.587 & -0.032 & -0.12 & 0.06 & 0.563 \\
\hline Mood disorder & -3.05 & & -0.361 & 0.069 & -0.095 & & -0.013 & 30.06 \\
\hline Educational situation & -0.273 & -1.466 & 1.033 & 0.736 & -0.022 & -0.117 & 0.079 & 0.725 \\
\hline $\begin{array}{l}\text { Supplementation } \\
\text { with folic acid }\end{array}$ & 8.834 & 4.57 & 13.376 & 0.002 & 0.18 & 0.098 & 0.27 & 0.00 \\
\hline Use a tooth & -1.415 & -2.639 & -0.544 & 0.004 & & & -0.019 & 90.003 \\
\hline $\begin{array}{c}\text { Calcium } \\
\text { supplementation }\end{array}$ & 1.985 & 0.218 & 3.773 & 0.059 & 0.102 & 0.016 & 0.193 & 0.04 \\
\hline Tobacco & -0.849 & -4.004 & 2.175 & 0.63 & -0.026 & -0.126 & 0.066 & 0.617 \\
\hline Attachment loss & -4.369 & -6.269 & -2.527 & 0.001 & -0.207 & -0.299 & -0.124 & 40.001 \\
\hline Gestational diabetes & -5.713 & -10.179 & -1.039 & 0.04 & & & -0.024 & 40.033 \\
\hline $\begin{array}{c}\text { Pregnancy } \\
\text { hypertension }\end{array}$ & -8.887 & -12.422 & -5.869 & 0.001 & -0.236 & -0.336 & -0.164 & $\begin{array}{c}< \\
0.001\end{array}$ \\
\hline PROM & -6.336 & -12.402 & 0.553 & 0.123 & -0.086 & -0.167 & 0.001 & 0.103 \\
\hline PPROM & 0.06 & -11.619 & 10.553 & 0.984 & 0.001 & -0.094 & 0.086 & 0.984 \\
\hline Hypertension & 0.24 & -3.435 & 3.501 & 0.934 & 0.006 & -0.089 & 0.092 & 0.93 \\
\hline Diabetes & -1.484 & -5.092 & 2.304 & 0.514 & -0.036 & -0.119 & 0.052 & 0.495 \\
\hline & & 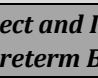 & (2) & & & 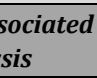 & & \\
\hline
\end{tabular}

The analysis of conceptual model, the removal of collinear variables, and addition of the relationship between the variables showed a statistically significant relationship between preterm birth and the following factors: maternal age $(\mathrm{P}=0.001)$, lack of folic acid supplementation $(\mathrm{P}=0.001)$, not using toothbrushes regularly $(\mathrm{P}=0.003)$, absence of calcium supplementation $(\mathrm{P}=0.048)$, periodontal attachment loss $(\mathrm{P}=$ 0.001), gestational diabetes $(\mathrm{P}=0.033)$ and gestational hypertension $(\mathrm{P}<0.001)$.

The path analysis method was intentionally used to accurately analyse the direct and indirect relationships of the specific risk factors carefully studied on the patient outcome of preterm delivery. First, the relationships of these variables were drawn based on previous studies and biological reasoning of the relationships between them (Figure 1). The final model after deleting some variables due to homogeneity and statistical considerations is shown in Figure 2.

Maternal age $(\mathrm{P}=0.003)$ folic acid supplementation $(\mathrm{P}=$ 0.002), periodontal attachment loss $(\mathrm{P}=0.001)$ and gestational diabetes $(\mathrm{P}=0.033)$ after accurately analysing the conceptual model and then removing collinear variables and adding the relationship between used variables, there was a direct statistically significant association with the risk of preterm birth. 


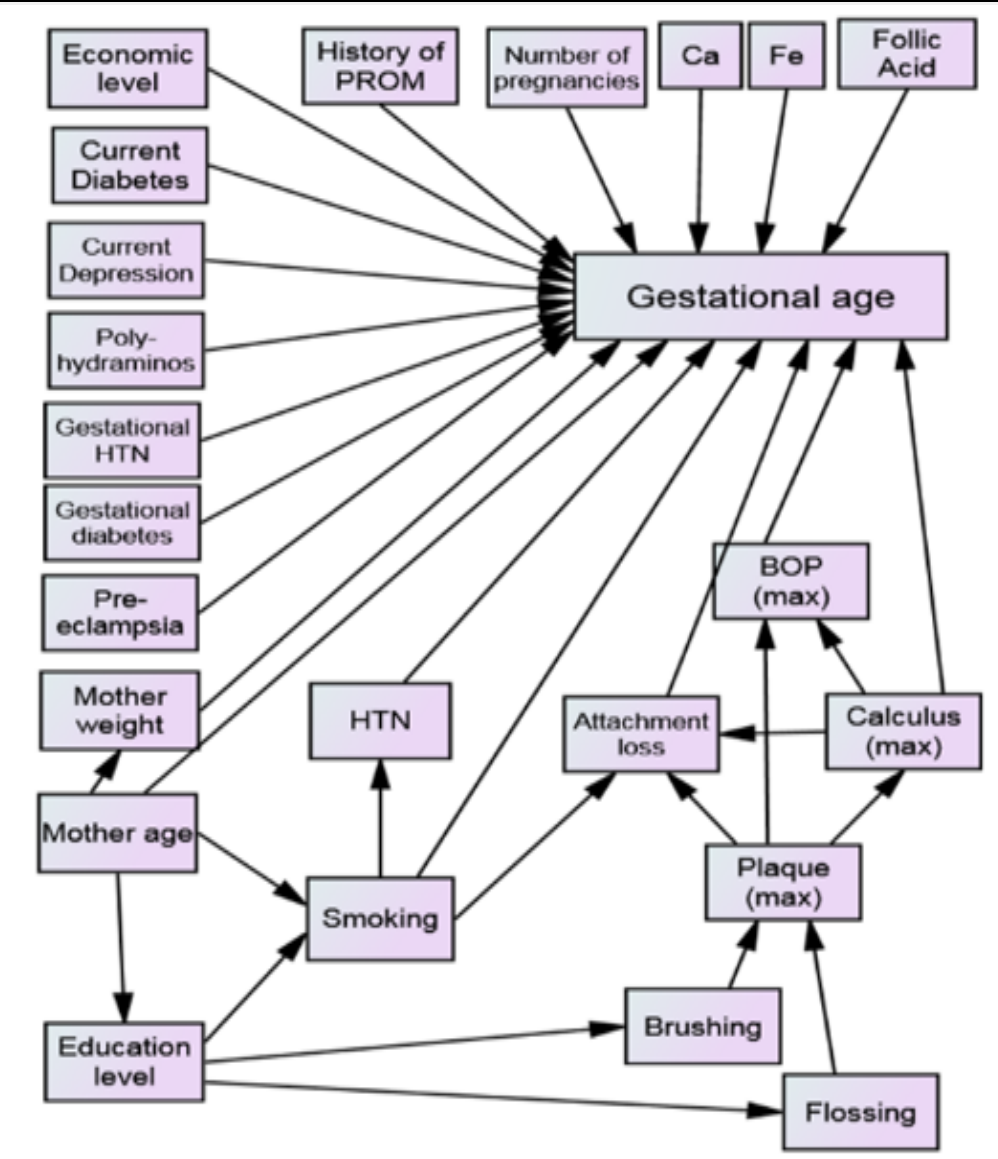

Figure 1. Conceptual Model of Preterm Labor

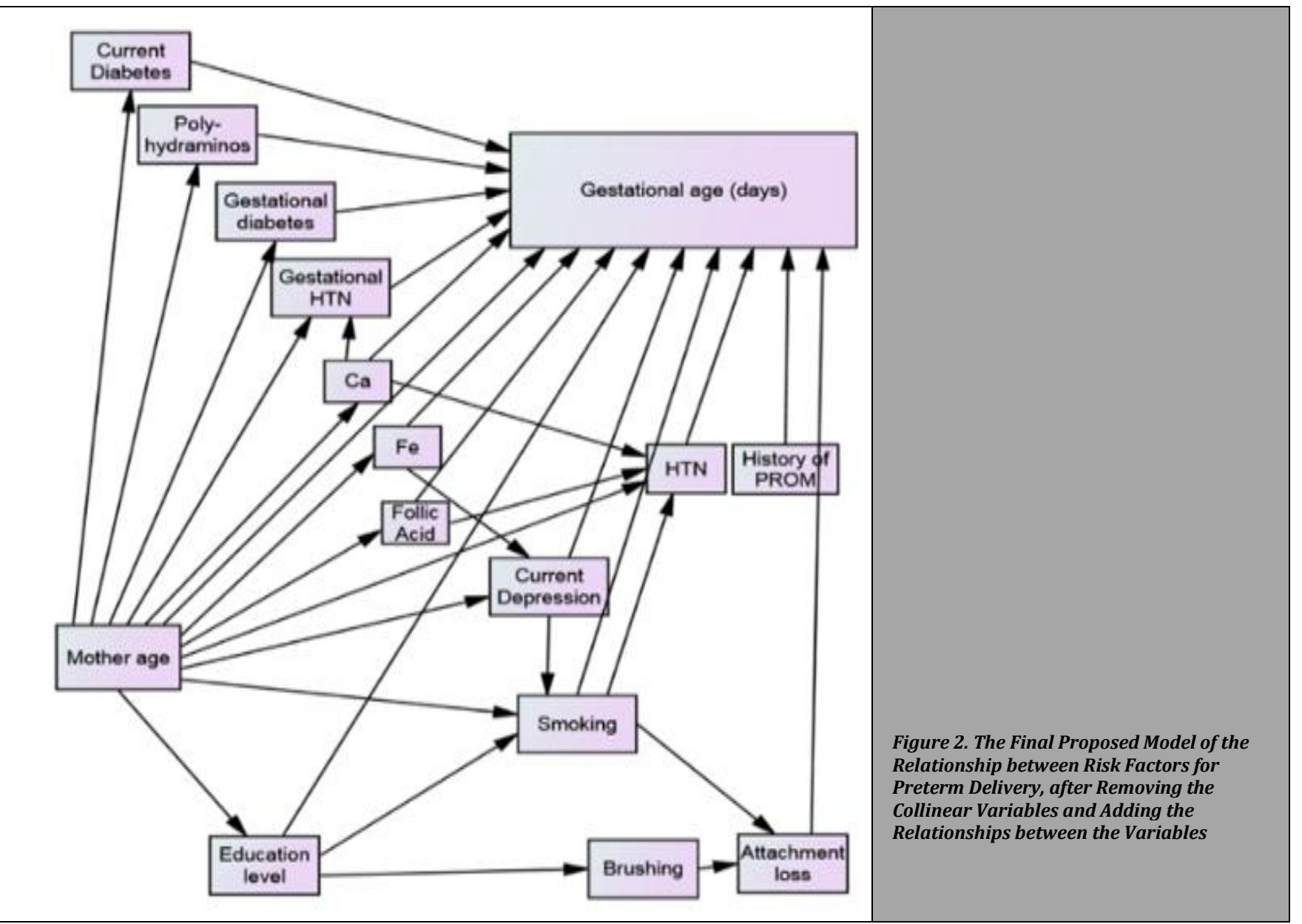




\begin{tabular}{|c|c|c|c|c|c|c|c|c|}
\hline \multirow{3}{*}{ Characteristics } & \multicolumn{8}{|c|}{ Direct Effects } \\
\hline & \multicolumn{4}{|c|}{$\begin{array}{l}\text { Unstandardized } \\
\qquad 90 \% \text { CI }\end{array}$} & \multicolumn{3}{|c|}{$\begin{array}{l}\text { Standardized } \\
90 \% \\
\text { CI }\end{array}$} & \multirow{2}{*}{ Palue } \\
\hline & Effect & Lower & Upper & $\begin{array}{c}\mathbf{P} \\
\text { Value }\end{array}$ & Effect & Lower & Upper & \\
\hline Age & 0.363 & 0.172 & 0.552 & 0.003 & 0.178 & 0.082 & 0.269 & 0.003 \\
\hline $\begin{array}{c}\mathrm{Fe} \\
\text { supplementation }\end{array}$ & -1.921 & - 7.918 & 4.434 & 0.642 & -0.028 & $3-0.117$ & 0.063 & 0.611 \\
\hline Mood disorders & -2.82 & -5.813 & 0.052 & 0.104 & -0.087 & $7-0.181$ & -0.003 & 30.09 \\
\hline $\begin{array}{l}\text { Educational } \\
\text { situation }\end{array}$ & -0.458 & -1.688 & 0.861 & 0.559 & -0.036 & $6-0.132$ & 0.064 & 0.545 \\
\hline $\begin{array}{c}\text { Folic acid } \\
\text { supplementation }\end{array}$ & 8.892 & 4.451 & 13.406 & 0.003 & 0.181 & 0.096 & 0.272 & 0.00 \\
\hline $\begin{array}{c}\text { Calcium } \\
\text { supplementation }\end{array}$ & 1.437 & -0.22 & 3.258 & 0.159 & 0.074 & -0.009 & 0.164 & 0.142 \\
\hline Tobacco & -0.584 & -3.643 & 2.522 & 0.765 & -0.018 & $3-0.109$ & 0.077 & 0.758 \\
\hline Attachment loss & -4.369 & -6.269 & -2.527 & 0.001 & -0.207 & $7-0.299$ & -0.124 & 40.001 \\
\hline $\begin{array}{c}\text { Gestational } \\
\text { diabetes }\end{array}$ & -5.713 & -10.179 & -1.039 & 0.04 & -0.111 & $1-0.196$ & -0.024 & 0.033 \\
\hline $\begin{array}{c}\text { Gestational } \\
\text { hypertension }\end{array}$ & -8.887 & -12.422 & -5.869 & 0.001 & -0.236 & $6-0.336$ & -0.164 & $\begin{array}{c}< \\
0.001\end{array}$ \\
\hline PROM & -6.336 & -12.402 & 0.553 & 0.123 & -0.086 & $6-0.167$ & 0.001 & 0.103 \\
\hline PPROM & 0.06 & -11.619 & 10.553 & 0.984 & 0.001 & -0.094 & 0.086 & 0.984 \\
\hline Hypertension & 0.24 & -3.435 & 3.501 & 0.934 & 0.006 & -0.089 & 0.092 & 0.93 \\
\hline Diabetes & -1.484 & -5.092 & 2.304 & 0.514 & -0.036 & $6-0.119$ & 0.052 & 0.495 \\
\hline
\end{tabular}

\begin{tabular}{|c|c|c|c|c|c|c|c|c|}
\hline \multirow{3}{*}{ Characteristics } & \multicolumn{8}{|c|}{ Indirect effects } \\
\hline & \multicolumn{4}{|c|}{$\begin{array}{c}\text { Unstandardized } \\
90 \% \mathrm{CI}\end{array}$} & \multicolumn{4}{|c|}{$\begin{array}{l}\text { Standardized } \\
90 \% \mathrm{CI}\end{array}$} \\
\hline & Effect & & Upper & $\begin{array}{c}P \\
\text { Value }\end{array}$ & Effect & t Lower & Upper & $\begin{array}{c}P \\
\text { Value }\end{array}$ \\
\hline Age & 0.062 & -0.054 & 0.176 & 0.333 & 0.03 & -0.027 & 0.086 & 0.343 \\
\hline $\begin{array}{c}\mathrm{Fe} \\
\text { supplementation }\end{array}$ & -0.245 & -1.431 & 0.301 & 0.385 & -0.004 & -0.021 & 0.004 & 0.37 \\
\hline Mood disorders & -0.23 & -1.165 & 0.57 & 0.584 & -0.007 & & 0.017 & 0.567 \\
\hline $\begin{array}{r}\text { Education } \\
\text { situation }\end{array}$ & 0.184 & 0.017 & 0.419 & 0.078 & 0.015 & 0.002 & 0.033 & 0.074 \\
\hline $\begin{array}{c}\text { Folic acid } \\
\text { supplementation }\end{array}$ & -0.058 & -0.896 & 0.847 & 0.9 & -0.001 & -0.018 & 0.017 & 0.886 \\
\hline Use a toothbrush & -1.415 & -2.639 & -0.544 & 0.004 & -0.046 & -0.088 & -0.019 & 0.003 \\
\hline $\begin{array}{c}\text { Calcium } \\
\text { supplementation }\end{array}$ & 0.548 & 0.071 & 1.202 & 0.064 & 0.028 & 0.004 & 0.06 & 0.056 \\
\hline Tobacco & -0.265 & -1.114 & 0.465 & 0.487 & -0.008 & -0.034 & 0.015 & 0.49 \\
\hline \multicolumn{9}{|c|}{$\begin{array}{l}\text { Table 3. Indirect Factors Associated with } \\
\text { Preterm Labour by Path Analysis }\end{array}$} \\
\hline
\end{tabular}

Using multivariate logistic regression, the variables that were independently associated with the outcome of preterm delivery were maternal age, calcium supplementation, folic acid supplementation, mood disorders, gestational hypertension, gestational diabetes, premature rupture of the bladder, and attachment loss. Table 4: Findings of multiple logistic regression analysis of factors related to preterm delivery are reported.

\begin{tabular}{|cccc|}
\hline Characteristics & $\begin{array}{c}\text { Adjusted Odds } \\
\text { Ratio }\end{array}$ & $\begin{array}{c}\text { 95 \% Odds } \\
\text { Ratio }\end{array}$ & P-Value \\
Age & & & \\
$<=24$ & 8.68 & $2.05-36.69$ & 0.001 \\
$25-34$ & 4.40 & $1.17-16.58$ & 0.03 \\
$>=35$ & 1 & & \\
Mood disorders & 2.52 & $1.01-6.3$ & 0.05 \\
Folic Acid supplementation & 0.20 & $0.05-0.77$ & 0.02 \\
Calcium supplementation & 0.49 & $0.26-0.92$ & 0.03 \\
Attachment loss & 4.73 & $2.54-8.81$ & 0.001 \\
Gestational diabetes & 4.07 & $1.04-15.91$ & 0.04 \\
Gestational hypertension & 5.82 & $2.03-16.63$ & 0.001 \\
\hline PROM & 8.39 & $1.17-60.33$ & 0.03 \\
\hline Table 4. Multiple Logistic Regression Analysis & \\
of Factors Related to Preterm Delivery & \\
\hline
\end{tabular}

\section{DISCUSSION}

Premature birth is the leading cause of infant mortality and is considered as one of the most important health priorities. Every year, 14.9 million babies are born in the world before 37 weeks. ${ }^{10}$ The prevalence of preterm delivery in various cities of Iran varies from 5.6 in Qom to $39.4 \%$ in Kerman. ${ }^{11}$

The main cause is unknown, about 40 to $45 \%$ of the cause are spontaneous, 25 to $30 \%$ are due to premature rupture of the membranes, and 30 to $35 \%$ happen due to medical issues, such as preeclampsia, intrauterine problems, and fetal growth restriction. Other causes include: lifestyle, smoking, maternal weight gain, adolescent or old age, poverty, vitamin C deficiency, depression, anxiety and chronic stress and long working hours per week, interval between pregnancies, history of preterm delivery, represent factors that increase the risk of preterm delivery. ${ }^{12}$ Genetic factors, periodontal disease, and infection are significantly associated with preterm labor. ${ }^{13}$

Periodontal disease in general is the most prevalent oral disease in pregnant women. Inflammatory disease can be one of the causes of premature birth and infant mortality which impose much emotional stress and medical expenses on families and society.

Understanding the impact of these risk factors can be helpful in planning national health programs. The results of this study showed that factors like age, socioeconomic status, maternal chance of mood disorders, gestational hypertension, preeclampsia, gestational diabetes, lack of calcium and folic acid supplementation increase the risk of preterm delivery. Oral health factors, including calculus, and bleeding on probing, attachment loss, and health factors, such as not brushing teeth can lead to premature delivery. Based on Path model analysis maternal age, gestational diabetes, attachment loss, and lack of folic acid supplementation are directly related to premature birth and regular tooth brushing is indirectly associated with the risk of premature birth. Similarly, in a study by Hammond (2013), factors influencing the early delivery in Western Australia, were maternal age at birth - less than 20 years and above 35 years, parity, marital status, diabetes, hypertension, asthma, genital herpes, a history of the earlier preterm, problems in previous pregnancies, preeclampsia, and anemia. ${ }^{14}$

Based on a study by Wong et al. (2013) in Taiwan, there was no significant relationship between periodontal disease and preterm birth. Indicators of periodontal disease in this study was plaque and bleeding on probing. In this examination, there was a significant correlation between plaque and grades 2 and 3 of bleeding on probing and preterm delivery. The possible reason for the contrast was the difference in population and the prevalence of periodontal disease and preterm birth between two countries, In Wong et al.'s study, the majority of cases were over 25 years and $90 \%$ were college students, and $10 \%$ had completed their school education and enjoyed a very good socioeconomic status. ${ }^{15}$

In our study, the samples were selected from among different people referring to receive prenatal care and this increases the generalizability of the results. The results of the study by Santos et al. showed that women with moderate to severe periodontal disease had a seven times greater risk of premature birth, which is compatible with the results of a recent study. ${ }^{16}$ The results of Lohsoonthorn's (2009) a case- 
control study showed that attachment loss was similar in both groups after delivery and there was no statistical association between periodontal disease and preterm labor. Recall bias in case-control studies and cultural and social differences in the samples of the two studies explain the reasons for the differences in the results of the two studies. ${ }^{17}$

In a prospective cohort study, Sirviva (2009) investigated the relationship between pregnancy outcomes with periodontitis in mothers with gestational age 6 - 20 weeks with an attachment loss of at least $3 \mathrm{~mm}$ and examined the effect of periodontal disease on pregnancy outcomes like premature birth and preeclampsia. The results showed that periodontal disease, the chances of preeclampsia, and preterm labor had increased to 0.71 and 0.77 , respectively. However, this observed association was not statistically significant.18 According to the findings, preeclampsia was not a direct or indirect cause of preterm delivery. Attachment loss, calculus, bleeding on probing are directly related to premature labor and irregular tooth brushing is indirectly associated with early birth.

No other studies, to date, used Path analysis to investigate factors affecting preterm labor, and this is the innovative aspect of the present study. For this reason, we had to use papers which were somewhat close to our method. The results of another study showed that the standard treatment of periodontal infection is safe in a successful pregnancy and typically improves periodontal disease. However, it does not significantly change preterm labor. ${ }^{14}$ This means that the treatment of a periodontal problem cannot prevent preterm labor. In this examination, mothers with periodontal disease were referred to a dentist for treatment, and received necessary health recommendations. A recent study sufficiently showed a direct link between periodontal disease and other contributing factors with preterm labor. It is recommended that a study be done on the relationship between prenatal treatment in the first and second trimesters of pregnancy and investigate their effect on preterm birth.

\section{CONCLUSIONS}

The results showed that factors such as attachment loss, calculus, BOP, age, gestational diabetes, gestational hypertension lack of calcium and folic acid and iron supplementation, depression in the mother, polyhydramnios, smoking severity, and history of premature rupture of the membrane are directly related to preterm labor and irregular tooth brushing is indirectly associated with early birth.

Data sharing statement provided by the authors is available with the full text of this article at jemds.com.

Financial or other competing interests: None.

Disclosure forms provided by the authors are available with the full text of this article at jemds.com.

This article is taken from the general Dental Dissertation No. 5048 of Tehran University of Medical Sciences. Special thanks to late Dr. Alireza Rasouli Ghahroudy, who was the first supervisor of this project. Researchers thank the officials school of Dentistry and mothers who participated in the study.

Permission was obtained from the ethics committee of Tehran University of Medical Sciences (No. 25839 - 69 - 03 - 93).

Written informed consent was obtained from mothers.

\section{REFERENCES}

[1] Gümüş P, Emingil G, Öztürk VÖ, et al. Oxidative stress markers in saliva and periodontal disease status: modulation during pregnancy and postpartum. BMC Infectious Diseases 2015;15(1):261.

[2] Bui FQ, Almeida-da-Silva CLC, Huynh B, et al. Association between periodontal pathogens and systemic disease. Biomed J 2019;42(1):27-35.

[3] Lieff S, Boggess KA, Murtha AP, et al. The oral conditions and pregnancy study: periodontal status of a cohort of pregnant women. J Periodontol 2004;75(1):116-26.

[4] Teshome A, Yitayeh A. Relationship between periodontal disease and preterm low birth weight: systematic review. Pan Afr Med J 2016;24(1):215.

[5] Gil L, Mínguez I, Caffesse R, et al. Periodontal disease in pregnancy: the influence of general factors and inflammatory mediators. Oral Health Prev Dent 2019;17(1):69-73.

[6] Da Rosa MI, Pires PDS, Medeiros LR, et al. Periodontal disease treatment and risk of preterm birth: a systematic review and meta-analysis. Cad Saúde Pública 2012;28(10):1823-33.

[7] Kim HJ, Jo MW, Bae SH, et al. Measuring the burden of disease due to preterm birth complications in Korea using disability-adjusted life years (DALY). Int J Environ Res Public Health 2019;16(3):519.

[8] Newman M, Takei H, Klokkevold PR, et al. Newman and Carranza's Clinical periodontology E-book. Elsevier Health Sciences 2018.

[9] Khakazan Z, Geranmayeh M, Taghizadeh J, et al. The survey of association between occupational factors and preterm childbirth. Hayat J Fac Nurs Midwifery 2008;13(4):5-14.

[10] Treherne SC, Feeley N, Charbonneau L, et al. Parents' perspectives of closeness and separation with their preterm infants in the NICU. J Obstet Gynecol Neonatal Nurs 2017;46(5):737-47.

[11] Dolatian M, Mirabzadeh A, Forouzan AS, et al. Preterm delivery and psycho-social determinants of health based on World Health Organization model in Iran: a narrative review. Glob J Health Sci 2013;5(1):52-64.

[12] Cunningham FG, Leveno KJ, Bloom SL, et al. Williams obstetrics. $2^{\text {th }}$ edn. New York: McGraw-Hill 2018.

[13] Robinson JN, Norwitz ER. Preterm birth: Risk factors, interventions for risk reduction and maternal prognosis. Up To Date 2018.

[14] Hammond G, Langridge A, Leonard H, et al. Changes in risk factors for preterm birth in Western Australia 1984 2006. BJOG 2013;120(9):1051-60.

[15] Wang YL, Liou JD, Pan WL, et al. Association between maternal periodontal disease and preterm delivery and low birth weight. Taiwan J Obstet Gynecol 2013;52(1):716.

[16] Santos-Pereira SA, Giraldo PC, Saba-Chujfi E, et al. Chronic periodontitis and pre-term labour in Brazilian pregnant women: an association to be analysed. J Clin Periodentol 2007;34(3):208-13.

[17] Lohsoonthorn V, Kungsadalpipob K, Chanchareonsook P, et al. Is maternal periodontal disease a risk factor for preterm delivery? Am J Epidemiol 2009;169(6):731-9. 
[18] Srinivas SK, Sammel MD, Stamilio DM, et al. Periodontal disease and adverse pregnancy outcomes: is there an association? Am J Obstetr Gynecol 2009;200(5):497. 